\title{
Livro-imagem: o trabalho realizado em uma sala de aula de Educação Infantil
}

\section{Wordless books: reading it in an Early Childhood Education classroom}

Renata Bozola é pedagoga graduada pelo Instituto Singularidades e bacharel em Direito pela PUC-SP. Atua na rede particular de ensino como professora de Educação Infantil e Ensino Fundamental.

\section{Contato: rebozola@hotmail.com}

\section{Resumo}

0 presente trabalho constitui-se em um relato de experiência das vivências em uma sala de aula de Educação Infantil com três livros-imagem da autora Suzy Lee: Onda, Espelho e Sombra ${ }^{1}$. Apesar de a leitura de histórias de diversos gêneros estar presente na rotina dos alunos dessa faixa de ensino, a turma em questão não havia travado contato com livrosimagem. 0 planejamento das atividades foi desafiador, em função da falta de bibliografia sobre o tema específico, o que motivou a realização deste trabalho. As atividades realizadas acabaram por envolver os alunos não só na leitura, mas também em questões envolvendo oralidade, escrita, artes, movimentos e brincadeiras. 0 resultado mostrou o quanto esses livros podem dar voz à imaginação e criatividade dos alunos da Educação Infantil, colocando o docente no lugar de protagonista da ação didática.

Palavras-chave: livro-imagem, Educação Infantil, Suzy Lee.

\section{Abstract}

This article describes the experience of reading wordless books Wave, Mirror and Shadow, by Suzy Lee, in an Early Childhood Education classroom. Despite reading stories of various genres is part of the routine of these students, they had not yet had contact with wordless books. Planning the

1. LEE, Suzy. Espelho. São Paulo: Cosac Naify, 2009; LEE, Suzy. Onda. São Paulo: Cosac Naify, 2010; LEE, Suzy. Sombra. São Paulo: Cosac Naify, 2011. 
activities was challenging due to the lack of literature on this issue, reason that motivated the creation of this article. The proposed activities engaged students not only in reading but also in speaking, writing, arts, movements and games. The result showed how much these books can challenge the imagination and creativity of the students and how they can establish a place of prominence in learning for teachers. Keywords: wordless book, Early Childhood Education, Suzy Lee.

\section{Introdução}

Minha infância sempre foi repleta de livros. Certamente por causa da paixão que minha mãe tinha por eles, na nossa casa podia não haver muito brinquedo, ou vestia-se roupa remendada, mas sempre havia livros. A paixão por livros passou de geração e cativou-me. Apesar disso, não me lembro de ter sido apresentada a nenhum livro-imagem ao longo da minha infância. Só viria a conhecê-los adulta, já no curso de graduação em pedagogia.

Mas afinal o que é um livro-imagem? É um livro sem palavras, que conta uma história apenas por meio de imagens. Segundo a definição de Van der Linden (2011) em Para ler o livro ilustrado, o livro-imagem é um "livro ilustrado onde as imagens constroem a narrativa sem a presença do texto verbal".

Confesso que, no início, achei aquilo tudo bem estranho, já que não havia um caminho a ser trilhado por palavras a seguir. Então, como ler aquele livro? Senti que a leitura seria bem mais difícil, pois exigiria uma análise das imagens: um olhar atento e pausado sobre cada detalhe e também sobre o todo. Após algumas leituras, percebi o quanto a leitura de livros-imagem exige uma participação ativa, já que o leitor exerce o papel de autor de uma história. Essa nova possibilidade de leitura me encantou e, por esse motivo, resolvi encantar meus alunos.

Além do protagonismo, as atividades com livros-imagem promovem a competência visual - que consiste em compreender uma imagem e apreciá-la de forma consciente e crítica - tão necessária perante a sociedade contemporânea, tão carregada de estímulos visuais.

Conforme as crianças desenvolvem uma narrativa própria, também desenvolvem a imaginação e a criatividade, tão importantes nos dias atuais. Como afirma Delors (2003, p. 100), 
"num mundo em mudança, de que um dos principais motores parece ser a inovação tanto social como econômica, deve ser dada importância especial à imaginação e à criatividade".

Antes de iniciar o trabalho, procurei por uma bibliografia que pudesse me ajudar a refletir e planejar as atividades, mas encontrei poucos livros relacionados à leitura de livros-imagem em sala de aula. Esse foi um dos motivos que me inspiraram a escrever este artigo: registrar o trabalho realizado e produzir um material para que outros professores pudessem refletir sobre as possibilidades de leituras de livros-imagem.

\section{Caracterização da unidade escolar}

Trabalho em uma escola particular bilíngue de Educação Infantil, localizada na zona sul da cidade de São Paulo. A escola está em funcionamento há sete anos e atende as famílias da comunidade da região. Além das salas de aula, o espaço é composto por quadra coberta, dois parques com brinquedos, tanque de areia, ateliê, biblioteca, sala de música e refeitório. As aulas ocorrem nos períodos da manhã, tarde e integral.

Sou professora do período integral da tarde, formado por nove crianças dos grupos 3 e 4. Essas crianças frequentam os grupos 3 e 4 pela manhã, almoçam na escola e permanecem no período integral à tarde. Nessa segunda parte do dia são realizadas atividades de artes, movimento, brincadeiras e leitura de histórias. A leitura de diversos gêneros é algo presente na rotina diária desses alunos. No entanto, até o início deste trabalho, a turma ainda não havia sido apresentada aos livros-imagem.

\section{0 trabalho realizado}

Ao longo do primeiro semestre de 2015, fiz uma sequência de atividades baseada na trilogia de livros-imagem da premiada autora e ilustradora sul-coreana Suzy Lee: Espelho, Onda e Sombra, publicados pela Editora Cosac Naify. I.I. Leitura e oralidade

Escolhi iniciar o trabalho com a leitura do livro Onda, por achar que a temática estava bem presente na vida das crianças frequentam praias com certa regularidade - e porque o elemento mágico não está presente nessa obra, como nas outras duas que integram a trilogia - o que dificulta a interpretação da história para um leitor não experiente. 
Não foi fácil escolher como eu faria a primeira leitura de um livro-imagem para aquelas crianças que nunca tinham tido - ao menos dentro da escola - um contato com esse tipo de livro, ainda que fossem crianças com convívio diário com livros.

Resolvi convidar os alunos - após a leitura do nome da autora, editora e título - a fazer previsões a respeito da história. De acordo com Moss (2002), antes da leitura de um texto literário, cabe à professora criar um cenário adequado para o contato literário, no qual convida os alunos a fazerem previsões a respeito da história que ouvirão. Para a autora, faz-se necessário um estudo da capa, do título, das ilustrações que precedem a história, entre outros elementos.

Portanto, partimos da questão: "Com base no título e na ilustração da capa, sobre o que vocês acham que é esse livro?" Além dessa, outras questões surgiram ao longo da nossa discussão: "Quem serão os personagens desse livro?"; "Em que lugar vocês acham que ocorre a história?".

Meu objetivo foi provocar uma discussão anterior à leitura, na qual os alunos colocassem em jogo seus conhecimentos prévios sobre o assunto - experiências na praia, com o mar e as ondas - antes de a história começar. Essa ativação de conhecimentos prévios seria de extrema relevância para que eles pudessem realizar uma leitura da obra. Segundo Moss (2002), a discussão anterior à leitura mostra como elas podem utilizar seus conhecimentos prévios para dar início a um novo processo de elaboração de significados.

As crianças identificaram a praia e a menina na ilustração da capa, contaram sobre suas vivências pessoais e previram que a história giraria em torno da menina e na praia - alguns alunos falaram que os pais ou amigos da menina também fariam parte da história. Retomei o título e perguntei como eles se relacionavam com as ondas do mar - alguns alunos falaram do medo e outros da brincadeira de pular onda.

Finalizada a discussão, anunciei o início da leitura. Virei a página, esperei uns dez segundos, em completo silêncio. Virei a página seguinte e permaneci mais dez segundos muda. As crianças me olhavam desconfiadas. Até que uma delas, não aguentando mais lidar com aquela situação de silêncio e estranhamento, disparou: "Você não vai ler? Por que você não lê? Qual parte você vai ler? Você tem que ler!" Eu joguei seus questionamentos para a turma: "Gente, mas por que eu não estou lendo?" E um menino respondeu: "Porque não tem nada escrito". 
Esse estranhamento já era esperado:

\begin{abstract}
Geralmente há uma surpresa inicial ante a falta de palavras escritas, mas qualquer preocupação sobre esta ausência tende a desaparecer com rapidez quando o leitor se dá conta da liberdade que esta ausência Ihe oferece - e começa a desfrutar de suas possibilidades criativas (SOLANA, 2014).
\end{abstract}

Diferentemente do livro ilustrado, no qual a criança ouve a história lida por um adulto e vê as imagens como uma ilustração do que está escrito, no livro-imagem as crianças possuem um papel mais ativo, já que são convidadas a agir como autoras e criar uma história baseada no que veem, sendo uma excelente forma de desenvolvimento da imaginação e da criatividade.

A partir do momento em que os alunos perceberam a ausência do texto, iniciamos uma discussão sobre como leríamos o livro, e concluímos que deveríamos "olhar as imagens e falar a história".

Passou-se, então, a estabelecer uma nova relação com esses livros. Voltei para a página inicial da história e as crianças começaram a descrever as cenas em voz alta - falando o que viam página a página.

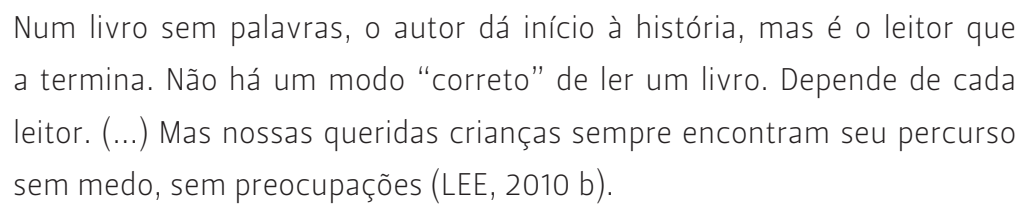

Em alguns momentos achei que uma intervenção era necessária, especialmente em pontos nos quais só a descrição da cena não seria suficiente para compreendê-la, sendo preciso perceber os sentimentos envolvidos.

Nessas ocasiões fiz perguntas, baseada na autora Solana (2014), que, ao descrever o processo de leitura de livros-imagem, trata da importância de os leitores serem guiados por questões como "o que me faz sentir?" e "o que me faz pensar?"

Para exemplificar: na cena em que a personagem está mostrando a língua para a onda, questionei: "Quando vocês mostram a língua para alguém, o que estão querendo provocar? Como se sentem?"; na cena em que a personagem está com os braços levantados gritando para a onda, questionei: "Qual sentimento vocês acham que ela está expressando?"

Em muitos momentos me surpreendi com a criatividade das crianças em preencher lacunas do livro - algumas para as quais eu 
mesma ainda não tinha uma interpretação definida. Em uma das cenas do livro a personagem toca o espelho e manchas aparecem na página. Um dos alunos não hesitou em dizer que eram bolhas de sabão, enquanto outro disse que era mágica. Isso mostra o quanto a narrativa é aberta e permite múltiplas interpretações.

Depois dessa primeira leitura, fizemos várias outras nesse mesmo formato coletivo, com as crianças tendo a oportunidade de expor oralmente, perante o grupo, as suas criações, desenvolvendo a linguagem oral - já que descreveram as imagens e narraram uma história, apropriando-se de vocabulário e buscando estruturas gramaticais adequadas. Percebi que a cada leitura conseguíamos nos aprofundar mais em algum detalhe.

Após muitas leituras, perguntei se alguém gostaria de contar a história, e muitos deles quiseram. Começamos, então, a fazer leituras individuais: um aluno contava a sua história para o grupo, com o apoio do livro.

A primeira leitura dos outros dois livros da autora não foram tão impactantes - apesar de os alunos sempre me perguntarem "esse também não tem palavras?" -, demonstrando conhecimento prévio do trabalho da autora. A dinâmica de leitura acabou sendo muito parecida com a do livro Onda: primeiramente fizemos várias leituras coletivas, em que pudemos conhecer a obra e analisar as cenas, e depois algumas individuais.

\section{I.II. Escrita}

Quando iniciei a sequência de atividades, não tinha como objetivo desenvolver a linguagem escrita. Mas, por sugestão da coordenadora pedagógica da escola, propus aos alunos que escrevêssemos uma história para um dos livros - uma história que nós já contávamos oralmente em nossas rodas de leitura.

Após uma votação, os alunos decidiram escrever a história do livro Espelho. Pegamos um bloco de folhas e começamos a escrevê-la, página a página, eu atuando como escriba. 0 tempo do processo de escrita foi bem livre: em alguns dias só escrevíamos o texto para uma página, em outros - quando os alunos estavam mais entretidos - escrevíamos várias. Sempre que íamos começar, eu relia o que já havia sido escrito. Todos os alunos participaram alguns dando muitas ideias e textos prontos, outros concordando ou discordando dos colegas. 
0 resultado ficou bem interessante e acabou registrando a história que aqueles alunos criaram. Em outros momentos, lemos a história escrita por eles - da qual ficaram muito orgulhosos.

\section{I.III. Artes e movimento}

A sequência de atividades proposta também abrangeu outras disciplinas, como artes visuais e teatro. A seguir, descrevo as principais atividades relacionadas a cada um dos livros.

I.III.a. 0 trabalho de artes realizado com o livro Onda: recontando uma história por meio da arte

Pensando em uma forma de registrar o trabalho realizado com o livro Onda, propus para os alunos uma atividade de artes baseada no cenário descrito, a praia. 0 suporte escolhido foi uma folha de cartolina branca, na qual colei uma intervenção: um decalque da personagem do livro em diferentes situações (sentada, mostrando a língua, gritando, entre outras). As técnicas utilizadas foram colagem e pintura, e os materiais oferecidos foram cola, areia colorida, tinta azul e pincel grosso. Meu objetivo era que as crianças, com esses materiais, pudessem construir cenários para a personagem e verificar se fariam relações com a história do livro.

0 processo de criação dos alunos foi surpreendente, e muito distinto entre as crianças. Um aluno colou areia sob os pés da personagem e, com uma única pincelada, fez uma onda aproximando-se dela. Enquanto pintava, ele falava: "A onda veio chegando perto e mais perto, e quase molhou ela". Outro aluno iniciou com pinceladas curtas longe da personagem e, aos poucos, foi chegando mais perto e narrando suas ações: "Agora essa onda chegou perto; essa molhou só um pouquinho; agora vai molhar a cabeça; molhou o pé (...)". Ao final cobriu toda a página com tinta e disse: "Agora a onda vai pegar ela e molhar ela toda". Uma aluna fez um círculo de areia ao redor da personagem e pintou de azul somente fora do círculo. Ela nomeou o círculo de castelo e, enquanto pintava, falava que o castelo iria proteger a menina das ondas do mar. 


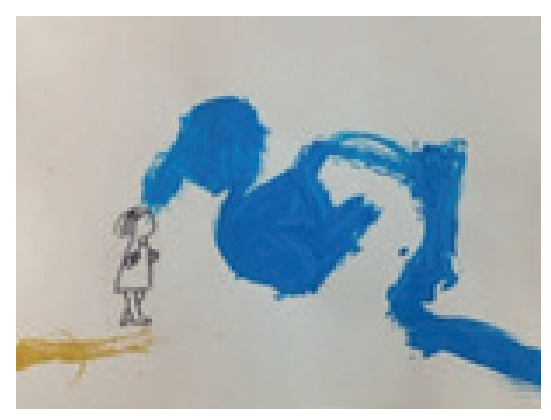

Figura 1 - Pintura e colagem de um dos alunos baseada no livro Onda.

\section{I.III.b. Brincadeiras corporais com o livro Espelho}

As atividades corporais com o livro Espelho não foram uma ideia que eu tive de início, mas algo que as próprias crianças foram me mostrando ao longo de nossas leituras. Muitas vezes, enquanto líamos, percebia que muitas faziam as poses da personagem e, sempre que eu perguntava como a personagem estava se sentindo naquele momento, eles faziam seus movimentos antes de falarem.

Isso me fez refletir sobre como o corpo também é um recurso que nos auxilia na leitura de um livro sem palavras.

Esta ideia de livro "silencioso" ou "mudo" sugere que é o leitor quem tem que colocar a "voz". Assim, como o criador da obra convoca toda sua habilidade como artista e contista para oferecer uma história, o leitor tem que valer-se de todas as suas competências narrativas, visuais e até dramáticas para dar essa voz ao texto visual (SOLANA, 2014).

Em decorrência dessa constatação, propus leituras dramatizadas, nas quais as crianças eram livres para explorar seus movimentos. Essa movimentação contribuiu muito para a compreensão do livro e para uma leitura mais profunda da obra. Além disso, as crianças puderam explorar diversos movimentos e relacioná-los com sentimentos. Perguntei em muitos momentos qual sentimento estava envolvido naquela expressão: "0 que vocês sentem quando fazem esse gesto?"

Em outros momentos, fizemos leituras diante de um espelho, o que acabou virando uma brincadeira muito divertida em que os alunos exploraram suas expressões faciais e corporais e se autoconheceram. 


\section{I.III.c. Brincadeiras com o teatro de sombras}

Para acompanhar o trabalho de leitura do livro Sombra, decidi construir um teatro de sombras para as crianças explorarem e brincarem. Com uma caixa de papelão e papel de seda fizemos o palco.

Quando ficou pronto e fomos experimentar pela primeira vez, a curiosidade deles parecia transbordar. Um dos alunos queria ver se era realmente possível fazer a pomba com as mãos, como a personagem do livro fez. Quando fiz a pomba, ele ficou encantado e logo quis aprender.

Foram muitas as vezes em que brincamos com o teatro de sombras, e de muitas formas. Eles fizeram sombras com as mãos, com brinquedos disponíveis na sala, além de apresentações individuais e coletivas.

Em um segundo momento, desenhei em papel-cartão preto os personagens do livro - como o lobo, a pomba e a menina -, corteios e colei-os em palitos de sorvete.

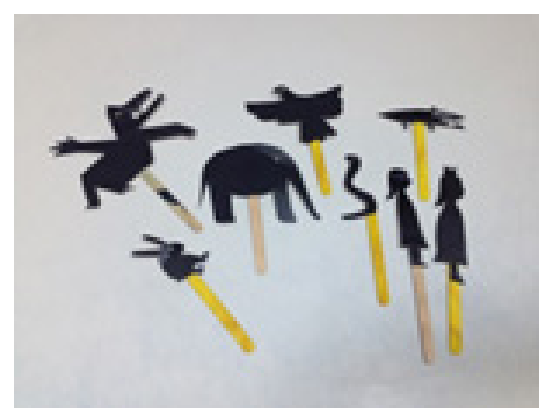

Figura 2 - Personagens do livro Sombra cortados e colados em palitos.

Entreguei para eles brincarem no nosso teatro de sombras e, novamente, fui surpreendida pelo resultado do trabalho. As crianças contaram e criaram muitas histórias - o lobo comeu muitos dos personagens que estavam lá, o elefante assustou o lobo, a princesa dançou com os animais, entre muitas outras fantasias que ocorreram ali.

\section{Conclusão}

A realização deste trabalho em uma sala de aula de Educação Infantil possibilitou o desenvolvimento de diferentes capacidades e habilidades. 
Primeiramente, os alunos conheceram livros-imagem e criaram uma estratégia de leitura - contribuindo para a formação do leitor literário. Acredito que, ao se depararem com outro livroimagem ao longo de seus percursos leitores, já não sentirão o estranhamento decorrente da ausência da palavra escrita e serão capazes de adotar uma estratégia de leitura baseada na leitura de imagens. A leitura de imagens foi outro aspecto que as crianças puderam desenvolver ao longo do trabalho. Em nossas leituras, as crianças analisaram as imagens dos livros com o intuito de compreendê-las e apreciá-las, buscando cada vez mais detalhes e informações. Outro aspecto relevante do trabalho foi o desenvolvimento da imaginação e da criatividade na construção da narração. Nesses momentos, as crianças atuaram como autoras de uma história, criando diferentes possibilidades e interpretações baseadas nas imagens.

Outro destaque da experiência foi dar a voz aos alunos. Eles tiveram total liberdade de expressão para falar sobre suas interpretações. Nesse momento apareceram múltiplas interpretações de trechos dos livros - o que possibilitou o desenvolvimento de uma escuta respeitosa de opiniões diversas apresentadas pelos colegas, ajudando no fortalecimento de valores como respeito e direito à diversidade de opinião.

As brincadeiras com sombras e movimentos e expressões corporais e faciais aumentaram o repertório cultural de brincadeira das crianças, bem como aprofundaram o autoconhecimento.

0 trabalho com livros-imagem possibilitou, conforme descrito acima, múltiplas aprendizagens. A autora Solana trata do assunto no trecho a seguir:

\footnotetext{
A experiência vivida com o "livro álbum sem palavras" pode ajudar o desenvolvimento de uma criança de uma forma significativa, não só como leitora mas também como ser humano porque the proporciona um espaço flexível no qual imaginar, refletir e aprimorar em seu entendimento tanto da palavra e da imagem, como de si mesmo e dos demais. Fazendo eco a muitos outros leitores participantes de Travessias Visuais, Hassan (em Glasgow, proveniente da Somália) concluiu: "(o autor) está fazendo com que você pense por si mesmo quais devem ser as palavras (SOLANA, 2014).
}

Por fim, desejo que este trabalho possa promover uma reflexão sobre as possibilidades de leituras de livros-imagem em sala de aula e servir de inspiração para que mais professores trabalhem com esses livros. 


\section{REFERÊNCIAS}

DELORS, Jacques. Educação: um tesouro a descobrir. Brasília, DF: MEC/UNESCO, 2003. Disponível em: http://ftp.infoeuropa. eurocid.pt/database/000046001-000047000/000046258. pdf. Acesso em: 4/10/2015.

LEE, Suzy. Espelho. São Paulo: Cosac Naify, 2009. Onda. São Paulo: Cosac Naify, 2010 (2010a). Sombra. São Paulo: Cosac Naify, 2011.

As imagens de Lee. São Paulo: Cosac Naify. Entrevista concedida a Heloisa Prieto em 25/03/2010. Disponível em http://editora.cosacnaify.com.br/ blog/? p=2383. Acesso em: 4/10/2015 (2010a).

LINDEN, Sophie van der. (2006) Para ler o livro ilustrado. São Paulo: Cosac Naify, 2011.

MOSS, Joy F. Literary discussion in the Elementary classroom. Urbana: NCTE, 2002.

SOLANA, Evelyn Arizpe. Imagens que convidam a pensar: 0 "livro álbum sem palavras" e a resposta leitora. Traduzido por Sandra Mendrano. Revista Emília: fevereiro de 2014. Disponível em http://www.revistaemilia.com.br/mostra. php?id=380. Acesso em: 4/10/2015.

Recebido em: 16/10/2015.

Aceito em: 22/12/2015.

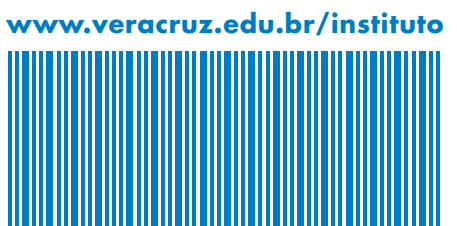

